\title{
The limitations of the methods of identifying the floral source of honeys
}

PETER MOLAN

The pollen grains in honey reveal the types of plants that were around when the bees produced the honey, thus it is valid to use melissopalynology to determine the geographical origin of honeys, but there are several reasons why it is less valid for determining the botanical origin of honeys.

\section{Introduction}

There are various reasons why the floral origin of a honey may be wanted to be known. For instance, for quality control in marketing, because of fair-trading legislation that requires correct descriptions on labels, and where there is regulatory concern about the country of origin of honeys. At present, possibly for lack of alternative methods, analysis of the pollen content of honey, termed melissopalynology, is used to determine the source of honeys. Pollen grains from different types of plants have a distinctive shape that allows the family, genus or often the individual species of plant that produced the pollen to be identified by microscopic examination of the pollen. Scanning electron microscopy allows even more to be identified at the level of the individual species. The pollen grains in honey reveal the types of plants that were around when the bees produced the honey, thus it is valid to use melissopalynology to determine the geographical origin of honeys (based on the characteristic flora of different regions), but there are several reasons why it is less valid for determining the botanical origin of honeys.
No honey produced by bees flying free is likely to be entirely unifloral. The term 'unifloral honey' is used to describe honey in which the major part of the nectar has been derived from a single plant species. For a honey to be called unifloral the pollen of the nominal species generally should be at least $45 \%$ of the total pollen count in the honey ${ }^{27}$. But this percentage does not apply when a floral source gives nectar with a higher or lower number of pollen grains than the average $^{25}$. Centrifugally extracted honeys produced from most species of plants contain between 20000 and 80000 pollen grains per $10 \mathrm{~g}$ of honey, but some nectar sources can be over-represented and others can be under-represented by their pollen in honey (with numbers up to 5 million and as low as 500). Conversion coefficients for over-represented and under-represented species, determined using experimentally produced single-source honeys, are available to allow the pollen count for each species to be normalized to more truly represent the proportion of each nectar in a multifloral honey ${ }^{27}$. But the proportion of pollen from the nominal species could be markedly reduced by incorporation of small proportions of nectars from 
species, not identified by the analyst, that are over-represented.

The absolute amount of pollen of the nominal species is a more reliable indicator of a honey being unifloral than is the proportion of that type of pollen present. The other types of pollen present may even not be indicating the presence of other types of nectar - they could have been incorporated by the nominal nectar being contaminated with these pollen grains brushed off bees that had been collecting just pollen. But although pollen coefficients (number of pollen grains per $10 \mathrm{~g}$ of honey) are available for many floral sources ${ }^{31}$ they are not always used in determining the sources of honeys. There are also other reasons, discussed below, why the results from melissopalynology may not be showing the nectar sources correctly.

There are some honeys that cannot have their source identified by melissopalynology. Honey that has been filtered with diatomaceous earth has no pollen left in it to be identified. Also honey produced from secretions of extrafloral nectaries (a major source of honey from cotton plants (Gossypium hirsutum), castor-oil plants (Ricinus cornmunis) ${ }^{7}$ and rubber trees (Hevea brasiliensis)e) and the honeydew secreted by sap-sucking insects will contain no pollen other than airborne grains that become trapped and which will not necessarily be from the plant that was the source of the secretion. There are also honeys which come from flowers such as those of the rewarewa (Knightia excelsa) that are pollinated by nectar-eating birds: bees can collect nectar from these flowers without dislodging pollen from the anthers.

Because of the limitations of identification of sources of honey by melissopalynology, and misleading conclusions that may be reached, other methods have been sought for the identification of the sources of honey. Also to be considered are the drawbacks of pollen analysis being time-consuming and very dependent on expert ability and judgement ${ }^{23}$, and the shortage of people with the necessary experience to be able to identify the myriad of pollen types found in honey ${ }^{11}$. Historically there has been an interest in identifying minor chemical components of honey that would serve as markers for particular floral sources, and a few have been recognized $^{5,6,24}$. But now that modern instrumental methods of analysis have been developed it is possible for patterns of constituents to be considered as 'fingerprints' for honeys from the various different floral sources. Although this is currently at the investigative stage, it shows, as discussed below, the potential to be a very useful technique once more data are collected. Chemical analysis also has the inherent advantage of being directly relevant to the source of the honey, the nectar, whereas melissopalynology is based on identification of components of honey that are peripheral to the nectar source and may vary for reasons that are unrelated to the nectar.

\section{Misleading results from identification by melissopalynology}

The contamination of honey from one floral source with pollen from other flowers can arise in the various ways, as outlined in the following sections. Clear evidence that this happens is the presence in honey of pollen from wind-pollinated species of plants and from some insect-pollinated plants which do not produce nectar ${ }^{29}$. One citrus honey has been reported to have $18 \%$ of its pollen content from kiwifruit (Actinidia deliciosa), which does not produce nectar ${ }^{29}$. Also reported is the finding in honey of pollen substitute that is fed to bees ${ }^{17}$. Although the recommended procedure of 
pollen analysis excludes from consideration pollens from floral sources that do not supply nectar ${ }^{25}$, the presence of these pollens in honey shows clearly that pollen is incorporated which is unrelated to the source of the nectar from which the honey is produced.

A study carried out in Canada ${ }^{1}$ has shown very clearly the unreliability of melissopalynology in determining the floral source of a honey. The pollen content of freshly collected nectar taken from beehives twice a week over an entire season of honey production was analysed. Lime (Tilia) was the predominant type of pollen in the incoming nectar over the first two weeks of the honey flow, then Lotus and Lythrum became the predominant pollen types in the nectar collected for the next few weeks. The average pollen count in the incoming nectar sampled twice weekly over this period was 20.9\% Tilia, with Lotus and Lythrum together making up $37.7 \%$. But the pollen count for the honey centrifugally extracted at the end of this period was only $6.7 \% \mathrm{Ma}$, with Lotus and Lythrum together making up $52.7 \%$. Yet weighing of the hives had shown that most of the honey had been produced in the first two weeks, when Tilia was the predominant type of pollen in the incoming nectar, and the honey had the distinctive colour and aroma of lime honey. This honey would not have been accepted as lime honey on the basis of its pollen analysis: more than $20 \%$ of the pollen would have to be from $\mathrm{Ma}$ for acceptance.

\section{Contamination from the actions of apiarists}

The worker bees foraging for pollen and those foraging for nectar each visit the flowers that are the best sources of each, thus pollen and nectar may be being collected from quite different floral sources on the same day ${ }^{18,32}$. Although the pollen harvested is stored mostly in the brood comb, some is also stored in pollen cells interspersed with honey cells in honey comb. When honey is extracted by crushing the combs, or when a 'loosening' device is used before extraction of thixotropic honeys (commonly done by plunging a sheet of needles repeatedly into the comb), the honey becomes contaminated with pollen that was not picked up with the nectar (i.e. from pollen storage cells in the comb).

Alternatively, honey is removed from the comb by cutting off the caps from the cells with a knife or some form of mechanical device before either draining or centrifuging the comb. Although in this type of extraction process most of the pollen remains in its storage cells in the comb, some will get spread from pollen storage cells to honey storage cells by the cutting process, again introducing to the honey pollen not associated with the nectar sources. The salvaging of honey by draining or centrifuging the 'cappings' which contain the crushed tops of both pollen and honey storage cells will introduce a much larger amount of pollen into the honey.

The widespread practice of re-using the extracted comb for production of the following season's honey crop is another common source of contamination. Pollen remains in the comb, especially in the pollen cells, when the comb is drained or centrifuged. This pollen will end up in the new honey that the bees pack into the comb. This new honey may be from completely different floral sources from those visited by the bees that collected the pollen the time before.

The proportions of different types of pollen present in the honey when it was extracted from the comb may be altered by the straining of honey that is carried out as part of the processing by apiarists. Pollen grains are 5-200 pm in diameter, but even the coarser fabric filter socks that are used for 
straining honey (i.e. with a pore size greater than $200 \mathrm{pm}$ ) may filter out pollen grains as debris builds up on the filter and effectively makes the pore size smaller. Different floral sources have pollen grains that are characteristically different in size. The larger pollen grains are more likely to be filtered, so there would then be a misleading abundance of the sources with smaller pollen grains.

\section{Variable contributions from the flowers}

The amount of pollen produced relative to the amount of nectar varies with different species of plants. Differences in flower anatomy also means that different amounts of pollen get into the nectar. The 'over-representation' and 'under-representation' of a floral source in honey resulting from high or low ratios of pollen to nectar is allowed for in quantitative pollen analysis, but wrong conclusions on identity could result from variations in the amounts of pollen that can occur within a source of nectar. For example, ling heather (Calluna vulgaris) is not a floral source generally recognized as being under-represented by its pollen in honey, but New Zealand producers of ling heather honey frequently have problems getting it accepted in other countries because of its low content of ling heather pollen ${ }^{29}$. It has also been reported that in parts of Europe an almost pure ling heather honey is produced in which ling heather pollen is secondary in proportion".

Temperature affects the release of pollen from anthers ${ }^{32}$, so if the climate varies from year to year it can be expected that the amount of pollen in nectar may vary also. Similarly, variation in pollen content could be expected during the honey flow from a floral source, and in the nectar collected from the same floral source in different locations where there are variations in temperature between locations.

Species of flowers differ in the relative tim- ing of nectar and pollen production. Variability can also result from sources that have flowers in which the male and female parts ripen at different times. In plants with separate male and female flowers the nectar yield may be different in each type of flower. Thyme (Thymus vulgaris) has on some plants only female flowers (which produce no pollen) and on other plants hermaphrodite flowers, the proportion of each type of plant (hence the proportion supplying pollen as well as nectar) depending on the environment ${ }^{15}$. So at different times and in different locations the amount of pollen associated with the nectar collected from a species of plant can be expected to vary. Also, bees may forage selectively from pollen-producing or pollen-free flowers of the same species of plants, which would give further variability in the pollen content of the nectar collected into different hives from the same floral source: bees from adjacent hives have been shown to harvest different sources of pollen ${ }^{18}$.

\section{Alteration of the pollen content of honey by the action of the bees}

The rationale for the use of melissopalynology to identify the floral source of honey is that the nectar collected by the bees contains pollen from its source. The nectar is produced by the nectaries at the base of flowers, but the pollen is produced by the anthers which are generally situated around the openings of flowers. In upright-facing flowers the pollen may fall into the nectar, or may be shaken in by bees visiting the flowers. (How pollen gets into the nectar of pendulous flowers remains to be explained.) But it is also possible that the pollen brushed into the nectar by a visiting bee may be that being carried from a completely different type of flower, picked up on the bee's fuzzy body as it brushed against the 
anthers of a previously visited flower. Thus pollen in the nectar at the base of a flower may have been shaken in from the body of a bee from a different hive visiting earlier, from flowers different from the type being harvested by a bee currently collecting the nectar.

Whether it is in the base of the flower or in the hive that the nectar is contaminated with pollen from a different floral source, the reliability of identification of the source by melissopalynology is compromised by the division of workers in the hive into foragers of nectar and foragers of pollen. To obtain enough pollen, bees have to forage from flowers over a considerably greater area than they do to obtain enough nectar ${ }^{32}$. Bees foraging for pollen work chiefly on the most abundant sources within their flight range, and collect from relatively few species of plants ${ }^{18}$. However, they seem to prefer pollen from a mixture of species to that from a single species, possibly to obtain a good balance of amino acids. If flowers being worked as a nectar source are also visited by pollen foragers, it could be expected that some of the mixed pollen carried on the bodies of the latter would be dislodged into the nectar as they roll against the anthers.

There is also scope for some of the mixed pollen collected by pollen foragers to be shaken into collected nectar in uncapped cells in the honeycomb that bees crawl over when putting pollen into storage cells. Or it may get into nectar from the mouth parts of the house bees, as the same house bees process both the nectar and pollen harvested by foraging worker bees. The house bees evaporate water from nectar by repeatedly regurgitating droplets on to their proboscis, then spread the liquid over the walls of the cells in the honeycomb for further drying to occur ${ }^{26}$. These same bees use their mouthparts to pack down and smooth out the pollen pellets brought in by pollen foragers, and to feed pollen to the brood in the hive. An experiment carried out with isotopically 'labelled' sugar fed to a colony showed a rapid spread of the label to all of the bees in a hive ${ }^{30}$, indicating a high degree of interaction between bees in a hive, and thus the possibility of an extensive spread of pollen.

The pollen content of the nectar collected can be altered by subtraction as well as by addition. Whilst the nectar is held in the bee's honey sac (crop), pollen is filtered out from it by the regulatory action of the proventriculus at the bottom of the crop. One half to two thirds of the pollen is removed within 15 minutes in this way ${ }^{26}$. Thus the amount of pollen in the nectar depends also on the length of time that a bee is out foraging for each load, and the length of the flight back to the hive.

\section{Determining the floral source by analysis of molecular components of honey}

Honeys vary widely in their aroma, flavour and colour, and these features are often characteristic of honeys from particular floral sources ${ }^{7}$. Thus chemical analysis of the components responsible for these features can be expected to show unique compositions that are characteristic of each floral source. Also there are components responsible for the unique flavour or aroma of some types of honey which can be expected to be found only in honeys from particular floral sources. These are potentially useful as 'markers' for those floral sources.

Methyl anthranilate was long ago found to be responsible for the distinctive aroma of orange blossom (Citrus sinensis) honey24.The major volatile component responsible for the aroma of sweet chestnut (Castanea sativa) honey has been found to be 3-aminoacetophenone ${ }^{6}$. The terpenes linden ether 
(3,9-epoxy-1,448j-p-menthadiene) and cis-rose oxide have been found to be the major components responsible for the aroma of linden (Tilio cordata) honey ${ }^{5}$. Methyl anthranilate is unique to orange blossom honey: it was not found in any other types of honey when numerous samples of non-citrus honeys were examined ${ }^{38}$. Likewise, linden ether and cis-rose oxide, also_the_odourless_terpene trans-8-p-menthen-1,2-diol, which were present in all of the samples of linden honey (and linden blossom) analysed, were not in any of the honeys from Robinia, Erica, orange blossom, rape and wild tobacco that were analysed. But although 3-aminoacetophenone was suggested to be specific for sweet chestnut ${ }^{6}$, it was not found in ten samples of sweet chestnut honey analysed by subsequent worker ${ }^{21}$.

This later work on sweet chestnut honey ${ }^{21}$ found that 2-aminoacetophenone served as a good marker, along with 1-phenylethanol. The work also involved a study of ten samples of linden honey, and found that ethylmethylphenol, estragole, and carvacrol served as good markers of this type of honey. But none of these compounds was unique to a floral source: as markers they had to be present above the levels at which they occur in other types of honey. (In the sweet chestnut honeys the levels of 2aminoacetophenone and 1-phenylethanol were $154-544 \mathrm{pg} / \mathrm{g}$ and $88-218 \mathrm{pg} / \mathrm{g}$ respectively, whereas in the ten samples each of honeys from ten other sources the levels were below $70 \mathrm{pg} / \mathrm{g}$ and $30 \mathrm{pg} / \mathrm{g}$.) Similarly, the odourless compound (S)-(+)-dehydrovomifoliol has been reported to be useful as an indicator of a heather honey ${ }^{22}$. It was found at a level of $186-264 \mathrm{pg} / \mathrm{g}$ in the four French heather honeys examined, and at $56 \mathrm{pg} / \mathrm{g}$ in the one Spanish one. The eight other floral honeys from various countries that were examined contained 0.03-6.02 Peg.
Other potential markers have been identified from analysis by capillary gas chromatography-mass spectroscopy (GCMS) of dichloromethane extracts of six different types of Australian honey ${ }^{20}$. It was noted that some compounds were present at high concentrations in some honeys and absent in others. Only the Eucalyptus honeys contained hexenyl butyrate; various methoxy aromatics were found only in the honey from Bursaria spinosa; acetoin was found in large amounts only in the honeys from the Eucalyptus and Banksia species.

There are two major limitations to using single compounds as markers of floral sources. One is that there are a very large number of floral types of honey that have never been subjected to analysis, and some of these could well be found to contain what are currently proposed to be unique markers of other floral sources. Another limitation is that there is a large variance reported in these markers even in the relatively small number of samples of each floral type that has been analysed. This may be due to the samples of supposedly unifloral honey being in fact of mixed source, or to there being a large variance in the nectar source as a result of variation in the environment of individual plants. Until the true mean level of markers in authentic samples of honey from each source is known, determined in many samples from a range of locations over several seasons, markers cannot be used to reliably determine the proportion of a particular nectar source in a honey. Even if true mean levels are known, the precision of the method in determining the proportion of a nectar source in a honey will still depend on the amount of variance there is between different authentic samples.

The use of the whole pattern of the components of honey has more potential than the use of single markers. It can serve as a distinctive 'fingerprint' of each type of honey 
even though the individual components occur in more than one type of honey. It also gives a much better chance, if multivariate analysis is used, of correctly determining the proportion of each nectar source in the honey: although any single component may vary a lot in a single nectar source, the probability is that random fluctuations of multiple components will cancel out each other.

\section{'Fingerprinting' honeys by analysis of trace organic constituents}

Although the characteristic floral odour of Piedmontese multifloral honeys was found to be due principally to phenylacetaldehyde, this compound was found in unifloral honeys from Robinia and clover as well ${ }^{4}$. However, the pattern of volatile components.(52 were identified in the study) seen on capillary GCMS analysis showed no meaningful difference over three successive seasons in the multifloral honey produced from the same locality. The patterns in the two types of unifloral honey also did not differ significantly over two successive seasons. But the patterns were distinctly different for each of the three types of honey, and the different components contributed significantly to the distinctive aromas of the different types of honey. Thus the whole pattern was a distinctive fingerprint of each type of honey, even though single compounds occurred in more than one type of honey.

The scope for each floral type of honey to have a unique fingerprint is very wide, as the number of trace organic components found in honeys is large:54 different hydrocarbons, 47 alcohols, 20 aldehydes, 27 ketones, 65 acids, 42 esters, 10 furans, diethyl ether and 1,1-diphenylhydrazine have been identified in honey by various researchers ${ }^{33}$. As well as these there are many unidentified peaks that have been found in gas chromatography of honeys.
The use of whole chromatograms as fingerprints was first suggested in 1962 by DÖrrscheidt and Friedrich ${ }^{16}$, who carried out some of the early packed-column GCFID analysis of honey. Only four of the 31 peaks they found on the chromatograms were common to the six different types of honey examined. Their work was later extended by the use of capillary $\mathrm{GC}^{9}$, and 50 compounds were found in 10 different honeys, with only three of these compounds common to all of the honeys. In work on unifloral sweet chestnut honey ${ }^{6}, 19$ of the 40 compounds identified had not previously been reported found in honey. The authors cautioned that these did not necessarily provide a unique fingerprint for sweet chestnut honey, but with such a large number of compounds it does appear likely that they may.

Attempts have been made to determine fingerprints for some New Zealand unifloral honeys $^{37}$. Diethyl ether liquid-liquid extracts of more than 200 samples of honey collected over four seasons have been analysed by $\mathrm{GCMS}^{33}$. The array of components present varied in their distribution and relative concentration enough to be sufficiently diagnostic to identify the floral sources of the honeys. The diacids, aromatic compounds and degraded carotenoids were found to be more related to the floral source than the aliphatic acids and hydrocarbons which are associated with the beeswax. The GC traces were found to be distinctive enough for even an untrained person to recognize the different patterns. The distinctive features of the GC-MS analyses have been published for honeys from: white clover (Trifolium repens), kanuka (Leptospermum ericoides) and manuka (Leptospermum scoparium)34; ling heather (Calluna vulgaris) ${ }^{35}$; thyme (Thymus vulgaris) and willow (Salix spp.) ${ }^{36}$; nodding thistle (Carduus nutans) ${ }^{4 D}$; vipers bugloss (Echium vulgare $)^{41}$. A follow-up study of more 
samples of manuka honey from a later season confirmed the earlier conclusions ${ }^{39}$.

To confirm the reliability of this technique for the identification of floral sources, it will be necessary to analyse a large number of samples of each floral type to determine the variation in concentration of the organic substances characteristic of a particular floral type, especially from season to season and across different localities. In addition, it is important that a very wide range of floral types is analysed to establish the uniqueness of the fingerprints found. It will also be necessary to establish the effects of storage on the composition of honey, as increases in some compounds ${ }^{10}$ and some loss of volatile components ${ }^{42}$ have been reported in honeys that have been stored. Work will also be required by statisticians on the multivariate analysis that will be needed to determine the proportions of different nectar sources present in a honey.

\section{Identifying the source of honeys by multivariate analysis of the amino acid composition}

The occurrence of amino acids in nectar is virtually universal ${ }^{3}$. The amino acid composition of individual nectars has been demonstrated to be constant and characteristic of the plant species despite variation in the volume and concentration of the nectar secretion resulting from environmental factors ${ }^{13}$. This would suggest that the amino acid composition of a honey will be characteristic of the floral source of that honey, but this is only partly the case because of the influence of the bees. Thus the patterns of amino acid composition of honeys have been found to be generally similar, but with some variations due to the types of nectar or honeydew from which the honeys are made $^{13}$.The relationship of amino acid composition to the nectar source is further weakened by the contribution from the bees depending on the amount of 'working' of the nectar involved. This depends on the water content which will vary between different floral sources, and on the rate of drying which will vary in different climates.

Nevertheless, it has proved possible to distinguish honeys from different sources by their amino acid composition. The first quantitative study of the amino acid content of eight different honeys showed sufficient difference between them to suggest that the source plants could be identified this way'2. In a subsequent study the amino acid composition of 98 samples of honey from four countries was determined ${ }^{13}$. The ratios of the amounts of various amino acids to each other were then calculated, and the results suggested that honeys from different countries could be distinguished by some of the ratios. In a subsequent report on statistical treatment of the analytical data ${ }^{14}$, the ratios for 16 samples of honey, several from each of the four countries, were then matched with the ratios for the other honeys. Data from 42 samples from other sources were also tested in the same way. With a $5 \%$ or less probability of it being due just to chance, 15 of the 16 were assigned to the correct country, and only one of the 42 from other sources was assigned to one of the four countries. It was calculated if honey from any of the four countries were mixed with $40 \%$ of honey from one of the other countries it would be detectable by it no longer matching its own group.

The variability within honeys from the same source is so great that it is not readily possible to determine the origin of a honey from the absolute amounts and relative proportions of the different amino acids present. However, by use of canonical variates analysis it was possible to discriminate between honeys from different countries ${ }^{19}$. (This is a statistical technique that is used widely for discriminating between groups 
within which there is high sample variability.) But the method needs testing on a much wider range of honeys before it can be concluded that it is suitable for distinguishing honeys from different floral sources.

\section{Conclusion}

The methods currently available for the identification of the floral sources of honeys are far from satisfactory. Even if pollen coefficients were used instead of proportions of types of pollen, melissopalynology is still likely to give rise to 'miscarriages of justice' when honeys are accepted or rejected as unifloral. Although there is the prospect of identification methods based on chemical analysis becoming available, a very large amount of work remains to be done to establish these. Until such time as this has been done, it should be borne in mind that it is not possible to identify the source of a honey with certainty, and the most reliable identification is likely to come from a combination of methods, including skilled organoleptic assessment. The latter, although a subjective measure, is after all based on the characteristics of a honey that the consumer is seeking.

\section{References}

1. ADAMS, R J; SMITH, M V (1981) Seasonal pollen analysis of nectar from the hive and of extracted honey. Journal of Apicuhural Research 20(4): 234-248.

2. BAKER, H C; BAKER, I (1977) Intraspecific constancy of floral nectar amino acid complements. Botanical Gazette 138(2): 183-191.

3. BAKER, H G; BAKER, I (1983) A brief historical review of the chemistry of floral nectar. In Bentley, B; Elias, T (eds) The biology of nectaries. Columbia University Press; New York, USA; pp 126-152.

4. BICCHI, C; BELLIARDO, F; FRATTINI, C (1983) Identification of the volatile components of some Piedmontese honeys. Journal of Apicultural Research 22(2): 130-136.

5. BLANK, I; FISCHER, K H; GROSCH, W (1989)
Intensive neutral odourants of linden honey. Zeitschrift fur Lebensmittel-Untersuchung and . Forschung 189: 426-433.

6. BONAGA, G; GIUMANINI, A G (1986) The volatile fraction of chestnut honey. Journal of Apicuhural Research 25(2): 113-120.

7. CRANE, E (1975) The flowers honey comes from. In Crane, E (ed) Honey: a comprehensive survey, Heinemann; London, UK; pp 3-76.

8. CRANE, E; WALKER, W; DAY, R (1984) Directory of important world honey sources. International Bee Research Association; London, UK; 384 pp.

9. CREMER, E; RIEDMANN, M (1964) Identifizierung von gaschromatographisch getrennten Aromastoffen in Honigen. Zeitschrift fir Naturforschung B 19(1): 76-77.

10. CREMER, E; RIEDMANN, M (1965) Gaschromatographisch Untersuchungen zur Frage des Honigaromas. Monatshefte fur Chemie 96(2): 364-368.

11. CROFT, $L$ (1983) UK beekeeping under threat. The Sunday Times, 20 February; London, UK; $p 22$.

12. CURTI, R; RIGANTI, V (1966) Richerche sigli aminoacidi del miele. Rassegna Chimica 18(6): 278-282.

13. DAVIES, A M C (1975) Amino acid analysis of honeys from eleven countries. Journal of Apicuftural Research 14(1): 29-39.

14. DAVIES, A M C (1976) The application of amino acid analysis to the determination of geographical origin of honey. Journal of Food Technology 11:515-523,

15. DOMMEE, B; ASSOUAD, M W; VADEYRON, G (1978) Natural selection and gynodioecy in Thymus vulgaris. Botanical Journal of the Unnean Society 77:17-28.

16. DORRSCHEIDT, W; FRIEDRICH, K (1962) Trennung von Aromastoffen des Honigs mit hilfe der Gas-Chromatogrphie. Journal of Chromatography 7(1): 13-18.

17. FOSSEL, A (1968) Pollenersatzmittel im mikroskopischen Befund von FrOhtrachthonigen. Zeitschrift fiir Bienenforschung 9(5): 206-211.

18. FREE, J B (1970) Insect pollination of crops. Academic Press; London, UK; 544 pp.

19. GILBERT, J; SHEPHERD, M J; WALLWORK, M A; HARRIS, R G (1981) Determination of the geographical origin of honeys by multivariate analysis of gas chromatographic data on their free amino add content. Journal of Apiculture! Research 20(2): 125-135.

20. GRADDON, A D; MORISON, J D; SMITH, J F (1979) Volatile constituents of some unifloral Australian honeys. Journal of Agricultural and Food Chemistry 27(4): 832-837. 
21. GUYOT, C; BOUSETA, A; SCHEIRMAN, V S C (1998) Floral origin markers of chestnut and lime tree honeys. Journal of Agricultural and Food Chemistry 46(2): 625-633.

22. HAUSLER, M; MONTAG, A (1989) Isolation, Identification and quantitative determination of the isoprenoid (S)-(+)-dehydrovomifoliol in honey.Zeitschrift fur Lebensmittel-Untersuchung und -Forschung 189: 113-115.

23. HOWELLS, V W (1969) Some reflections on the pollen analysis of honey. Journal of the Association of Public Analysts 7: 88-93.

24. LOTHROP, R E (1932) Specific test for orange honey. Industrial and Engineering Chemistry -Analytical Edition 4:395-396.

25. LOUVEAUX, J; MAURIZIO, A; VORWOHL, G (1978) Methods of melissopalynology. Bee World 59(4):139-157.

26. MAURIZIO, A (1975) How bees make honey. In Crane, E (ed) Honey: a comprehensive survey. Heinemann; London, UK; pp 77-105.

27. MAURIZIO, A (1975) Microscopy of honey. In Crane, E (ed) Honey: a comprehensive survey. Heinemann; London, UK; pp 240-257.

28. MAURIZIO, A; LOUVEAUX, J (1964) Pollens des plantes melliferes d'Europe. V. Pollen et Spores 6: 5-45.

29. MOAR, N T (1985) Pollen analysis of New Zealand honey. New Zealand Journal of Agricultural Research 28:39-70.

30. NIXON, H L; RIBBANDS, C R (1952) Food transmission within the honeybee community. Proceedings of the Royal Society of London, Series 140:43-50.

31. SAWYER, R (1988) Honey identification. Cardiff Academic Press; Cardiff, UK; 115 pp,

32. SHUEL, R W (1992) The production of nectar and pollen. In Graham, J M (ed) The hive and the honey bee. Dadant \& Sons; Hamilton, Illinois, USA; pp 401-436 (revised edition).

33. TAN, S T (1989) A chemical Investigation of some New Zealand honeys. DPhil thesis; University of Waikato; Hamilton, New Zealand.

34.TAN, S T; HOLLAND, P T; WILKINS, A L; MOLAN, P C (1988) Extractives from New Zealand honeys. 1 . White clover, manuka and kanuka unifloral honeys. Journal of Agricultural and Food Chemistry 36(3):453160.
35. TAN, S T; WILKINS, A L; HOLLAND, P T; McGHIE, T K (1989) Extractives from New Zealand unifloral honeys. 2. Degraded carotenoids and other substances from heather honey. Journal of Agricultural and Food Chemistry 37(5): 1217-21.

36. TAN, S T; WILKINS, A L; HOLLAND, P T; McGHIE, T K (1990) Extractives from New Zealand honeys. 3. Unifloral thyme and willow honey. Journal of Agricultural and Food Chemistry 38(9):1833-8.

37.TAN, S T; WILKINS, A L; MOLAN, P C; HOLLAND, P T; REID, M (1989) A chemical approach to the determination of the floral sources of New Zealand honeys. Journal of Apicultural Research 28(4): 212-22.

38. WHITE, J W (1966) Methyl anthranilate content of citrus honey. Journal of Food Science 31(1): 102-104.

39. WILKINS, A L; LU, Y; MOLAN, P C (1993) Extractable organic substances from New Zealand unifloral manuka (Leptospermum scoparium) honeys. Journal of Apicultural Research 32(1): 3-9.

40. WILKINS, A L; LU,Y; TAN, S T (1993) Extractives from New Zealand honeys. 4. Linalool derivatives and other components from nodding thistle (Carduus nutans) honey.Journal of Agricultural and Food Chemistry 41(6): 873-878.

41. WILKINS, A L; TAN, S T; MOLAN, P C (1995) Extractives from New Zealand unifloral vipers bugloss (Echium vulgare) honey. Journal of Apicultural Research 34(2): 73-78.

42.WOOTTON, $M$; EDWARDS, $R \quad A$; FARAJIHAREMI, R; WILLIAMS, P J (1978) Effect of accelerated storage conditions on the chemical composition and properties of Australian honeys 3. Changes in volatile components. Journal of Apicultural Research 17(3): 167-172.

\section{Peter C Molan}

Honey Research Unit, Department of Biological Sciences, University of Waikato, Private Bag 3105, Hamilton, New Zealand 